\title{
Further Evidence for Arabic Basic Colour Categories
}

\author{
Abdulrahman S. Al-rasheed \\ Departments of Psychology, King Saud University, Riyadh, KSA \\ Email: asalrasheed@ksu.edu.sa \\ Received 27 July 2014; revised 24 August 2014; accepted 18 September 2014 \\ Copyright (C) 2014 by author and Scientific Research Publishing Inc. \\ This work is licensed under the Creative Commons Attribution International License (CC BY). \\ http://creativecommons.org/licenses/by/4.0/ \\ c) (i) Open Access
}

\section{Abstract}

The aim of this study was to describe the basic colour terms (BCTs) of Arabic and, in particular, clarify the relationship among the three Arabic terms for blue: azrock, samawee, and khuhlie that suggested a BCTs in Arabic language in Al-rasheed et al. (2013). Data were collected from adult native Arabic speakers ( 30 male and 27 female) age between 18 and 34 years old, with a mean age of 21.67 years $(S D=2.98)$. All were under and postgraduate students at King Saud University. Participants task was to group the 320 colours by similarity. Based on this result, Arabic probably has eleven basic colour terms and these correspond with Berlin and Kay's eleven universal categories. The terms are that ahmar "red", akhdar "green", asfer, "yellow", azrock "blue", asswed "black", abiyadh "white", banafsagee "purple", boartoogaalee "orange", bonee "brown", wardee "pink" and rassasee. In addition, the terms of particular interest-samawee ("light blue") had the next highest claim to being basic and may deserve further investigating.

\section{Keywords}

Basic Colour Terms, Colour Categorisation, Universal Categories, Berlin and Kay's Theory, Arabic Language

\section{Introduction}

This paper reports a study of the "basic colour terms" (BCTs) of Arabic conducted within the framework of Berlin \& Kay's (1969) theory of universal colour categories. Previous work by Al-rasheed, Al-mohimeed \& Davies, 2013 had suggested that Arabic might have more than one BCT for the blue region—azrock "blue", samawee "light blue" and khuhlie "dark-blue" — and thus a subsidiary aim was to investigate this possibility.

The essence of Berlin and Kay's (1969) theory ${ }^{1}$ is that, although languages vary in the numbers of basic terms

${ }^{1}$ See Hippisley, Davies \& Corbett (2006) for a fuller account. 
they have and in the location of their category boundaries, all languages draw their inventories of BCTs from a set of eleven "universal" colour categories: [black white] red [green yellow] blue brown [purple pink orange grey]. These universal categories are characterised by their best examples or category foci, and if a language expresses a version of a universal category, then its best example should be similar to the appropriate universal focus. Terms earlier in the list (hierarchy), on average, are more likely to be represented than later terms; terms conjoined in parenthesis, are equally likely to occur. The first six terms (primary terms) were thought to be fundamental, in that they were aligned with fundamental states of early colour processing (Kay \& McDaniel, 1978), while the remaining terms (derived) were thought to be based on combinations of the primary terms. This conjecture turned out not to be true (e.g., see Jameson \& D’Andrade, 1997). Nevertheless, the empirical observation of greater prevalence of primary than derived terms across languages holds, and there is evidence that primary terms are more salient than derived terms even in languages with a full set of eleven terms (see below). The claim that best examples of equivalent categories are very similar in all languages has also been questioned (e.g., Ratner, 1989) but Kay, Paul, Regier, Terry \& Cook, (2005) show that although there may be exceptions, there is a strong statistical tendency for category foci to be very similar across languages.

\subsection{Beyond the Eleven}

Kay and McDaniel (1978) developed the Berlin and Kay (1969) theory using a system of fuzzy logic, consistent with the prototypical properties of natural categories (Rosch, 1973, 1975). Kay and McDaniel (1978) proposed that six fundamental neural responses (FNRs) were directly responsible for the perception and linguistic structure of what they called the "primary" colours-namely, black, white, red, green, yellow, and blue. They drew a distinction between two types of non-primary colour categories: composite and derived categories. Composite categories are the fuzzy union of two FNRs. For instance, it is common to have a single term that includes both the universal categories blue and green- - "grue”. Derived categories are the fuzzy intersection of two FNRs; so, for example, orange is the fuzzy intersection of red and yellow.

One implication of the Kay and McDaniel (1978) theory is that there are logically possible fuzzy unions and intersections that are not included in the Berlin and Kay (1969) hierarchy. For example, Zollinger (1984) argues that the space between blue and green is wide enough to be encoded by the term turquoise, derived from the fuzzy intersection of these two FNRs. Adding a blue term appears to be the most common way that languages move beyond the eleven Berlin and Kay basic colour terms (stage seven). Russian, (Davies \& Corbett, 1994), Turkish (Özgen \& Davies, 1998) and Greek (Androulaki, Gômez-Pestaña, Mitsakis, Lillo, Coventry, \& Davies, 2006) all have 12 BCTs, encoding the blue region with two basic terms distinguishing between light and dark blue. The extra blue term could either be the fuzzy intersection of blue and black, resulting in "dark blue", or the intersection of white and blue, resulting in "light blue". Pilot work suggested that Arabic might have three terms that designate different kinds of blue: azrock "blue", samawee "light blue" and khuhlie "dark-blue". The majority of our informants sorted the blue stimuli into groups that they named samawee "light blue" and azrock "blue”, suggesting that a more apt gloss for azrock may be "dark-blue”.

\subsection{BCT's of Arabic}

Al-rasheed et al., 2013 conducted a study aimed to established the "basic colour terms" (BCTs) of Arabic within the framework of Berlin \& Kay's (1969) theory of universal colour categories. Two tasks were used: a list task and a colour naming task. The list task is a simple and fast method of identifying likely BCTs (Davies \& Corbett 1994). It provides two measures—-frequency of use and order of occurrence-and assumes that the psychologically more salient terms will appear in more lists and in higher positions than less salient terms. Pich and Davies (1999) found that primary categories appeared more frequently than derived categories and that, in general, the 11 BCTs were used more frequently than non-BCTs. In the naming task, a representative sample of colour-stimuli (those used initially by Davies \& Corbett 1994) were named. BCTs should be used frequently and with consensus across informants. Two groups of Saudi Arabic speakers were tested, children and adults, both from Riyadh. However, as the pattern of results was essentially the same for the two groups, I only report here the adult data.

\subsubsection{Elicited Lists}

Two hundred adult informants, half were men and half were women, with an age range of 18 to 25 years (mean 
= 19.83) participated in this task. They were students at King Saud University and they were all native Arabic speakers with some knowledge of English. They were asked to write down as many colour terms as they could in two minutes.

Results of this experiment has shown that the terms ahmar, "red", akhdar, "green”, asfer, "yellow", azrock, "blue”, asswed, "black", banafsagee "purple" abiyadh, "white”, boartoogaalee, "orange”, bonee, "brown”, and wardee, "pink", were offered by a clear majority of the sample. Rassasee, "grey" was the next most frequent term offered by just under half the sample, while the two additional blue terms samawee "light blue" and khuhlie "dark blue" were offered by only about $30 \%$ of the sample.

\subsubsection{Colour Naming}

Sixty first language Arabic speakers from King Saud University named each of a standard set of sixty-five colours that used in (Davies \& Corbett, 1994 for their origin and technical specification). Al-rasheed et al. (2013), reported overall frequency of use for each term, and a measure of consensus - the dominance index. Basic terms should have high scores on both measures.

Result shows the frequency of use of each term across the colour set and sample (65 $\times 60$ possible responses). The child and adult results for the naming task provide that Arabic might has eleven BCTs that are consistent with Berlin and Kay's universal colour categories: asswed "black", abiyadh "white", ahmar "red", akhdar "green”, asfer "yellow”, azrock "blue”, bonee "brown”, banafsagee "purple”, wardee "pink", boartoogaalee "orange", and rassasee "grey". These are the same terms as suggested by the elicitation task. These terms have high frequency of use, are used with consensus as shown in Al-rasheed et al. (2013) by the dominance scores, and their use is relatively constricted to regions of high agreement as shown by high specificity scores. Moreover, estimates of the category foci reveal that they are similar to Berlin \& Kay's universal foci.

The additional blue term, samawee "light blue" had the $12^{\text {th }}$ highest frequency of use for the adults and $13^{\text {th }}$ for children; it was the most frequent term for one tile for both samples, and was dominant for the same tile for the adult sample. However, it too had the lowest specificity index of all terms with a nonzero dominance index. Azrock "blue", the likely BCT for blue, had a low specificity score for the children, and it was the only primary BCT not to be dominant for at the $90 \%$ level for at least one tile for the adults. This may be due to samawee "light blue" sometimes being used as an alternative (See Al-rasheed et al., 2013 for more details).

\subsection{Aims of the Current Study}

The overall aims of the present study were to determine the BCTs of Arabic and to explore the status of the putative extra blue terms. Fifty seven Arabic-speaking volunteers were tested, age range between 18 and 34 years old. The original A4 grid of the world colour survey was used. The status of the three blue terms azrock "blue", samawee "light blue" and khuhlie "dark blue" was of particular interest.

\section{Colour Mapping Experiment}

The finding of Al-rasheed et al., 2013 suggest that there are 11 basic colour terms for Arabic that reached the criteria of Berlin and Kay's (1969) universal terms. In contrast to the terms of particular interest, Samawee "light blue” in Al-rasheed et al., 2013 study: in the elicited lists task it was scored by nearly the majority of the child sample (40\%) and occupied position 12 of the most frequent, and mean list position, in the Adult and Child samples. For the colour naming task, it had one score in the number of tiles most frequent term across the sample (nmf) criteria in both samples also achieved dominance at the D50 criterion in the adult sample, but failed to achieve the D75 and the D90 criterion. These results in elicited lists and colour naming tasks still leave open the question of whether Samawee "light blue" is a basic colour term for Arabic. If it is true, it should identified as a basic term in the current study which was a colour mapping task.

In this study "colour mapping” 320 rectangle coloured representing the whole of colour space was used to allow for the more potential basic category Samawee "light blue" to be appeared. Two questions have been investigated, the former as the previous concerning the basic colour terms of Arabic, and the later concerning the location of the focal point of each of these basic categories. Participants were required to map the 320 chips by similarity and to give a name to each group, basic term are salient, and should be used by the high agreement of a language-sample. 


\subsection{Method}

\subsubsection{Participants}

A total of 57 Arabic-speaking volunteers took part in this study (30 male and 27 female) age between 18 and 34 years old, with a mean age of 21.67 years $(S D=2.98)$. All were under and postgraduate students at King Saud University and none of them had taken part in any of the two experiments in Al-rasheed et al. study (2013). All were first language Arabic speakers and knew a little English.

\subsubsection{Stimuli}

Stimuli were the original A4 grid used for the world colour survey (WCS) which consisted of a series of 320 coloured rectangles $(7 \times 5 \mathrm{~mm})$ formed in a rectangular grid shape. The columns represent 40 equally spaced Munsell hues, and the rows correspond to 8 levels of Munsell value (lightness) ranging from light to dark. Appendix 1 shows the array of the stimuli in Figure A1 and the location of the chips in the CIE ( $\left.u^{\prime} v^{\prime}\right)$ uniform chromaticity diagram in Figure A2 along with the CIE Yxy chromaticity coordinates in Table A1 in Appendix 2.

\subsubsection{Procedure}

Participants carried out the task in a lab and stimuli were illuminated from above by a general electric standard daylight fluorescent lamp (PHILIBS, E006, TLD 36 W/64 CA, Made in Holland, LS). Participants were tested individually male informants were tested by the author and female informants by female lecturer from King Saud University. None of the participants had taken part in any of the two experiments in the previous study of Al-rasheed et al., 2013.

All of the participants were firstly screened for normal colour vision with Ishihara's Test for Colour-Blindness (Ishihara, 1987) which took about five minutes. Then they were seated by a disk covered with a neutral grey cloth. The stimuli array was covered with a transparency and was presented on the table in front of participants. The participants were asked to group the 320 colours by similarity, so that they drew a line around those chips looked similar and members of a family. Participants then were asked to name each group using the simplest colour term that first came to their mind. Participants also were asked to indicate which chip in each grouped was the best example for the group.

\subsection{Results}

A name for each of the 320 Munsell chips in the WCS colour chart was obtained for each participant. Then a modal colour category obtained for each chip (the most frequent term associated to that particular chip). A visual representation map of the most frequent category used for each colour chip has been constructed. The Criteria in this study was used by Eleanor Rosch (1973 \& 1975), in her study of the Dani and as used in other studies (Heider, 1972, Heider \& Olivier, 1972; Davies \& Corbett, 1994; Pich, Jodi., \& Davies, 1999; Davidoff, Davies, \& Roberson, 1999; Regier, Kay, \& khetarpal, 2007; Uusküla, 2008). The distribution of categories and their focal points over the 320 Munsell chips in the WCS colour chart were shown in Figure 1(a) and Figure 1(b). Number in each chip in the array represents the name most frequently given to that chip.

Inspection of the result reveals a large area in green (91 chips out of 230) and blue (68 chips out of 230) regions, that Arabic sample performed similarly in this task as other languages (e.g., Berlin \& Kay, 1969; Davies \& Corbett, 1994; Kay, Berlin, Maffi, \& Merrifield, 1997 \& 2005; Kay \& Regier, 2003; Regier, Kay, \& Cook, 2005). Figure 1(b) shows the agreement percentage over $10 \%$ that a chip was given as a best example of each of the nine colour categories. The chip with the highest agreement was focal brown, it was chosen by $73 \%$, yellow $48 \%$, of the participants. Figure 2 shows the location of the best examples of the nine basic terms in the CIE uniform chromaticity space $\left(u^{\prime} v^{\prime}\right)$. Summaries of the average coordinates of the 9 categories were shown in Table A2 in Appendix 2.

Fifteen colour terms were produced to group the 320 rectangle coloured array by our participants. Nine terms appear to be basic Arabic colour categories. Thos terms are: ahmar "red", akhdar "green", asfer "yellow", azrock "blue”, banafsagee "purple", boartoogaalee "orange", bonee "brown", wardee "pink" and abiyadh "white". Summaries of the most frequent terms (over 10\%) used to name the 320 stimuli are shown in Table A3 in Appendix 2.

Table 1 summarises the results further. Column 3 shows the percentage frequency of each of the categories collapsed across all chips and all participants. The table is ordered by the frequency of occurrence of the term 


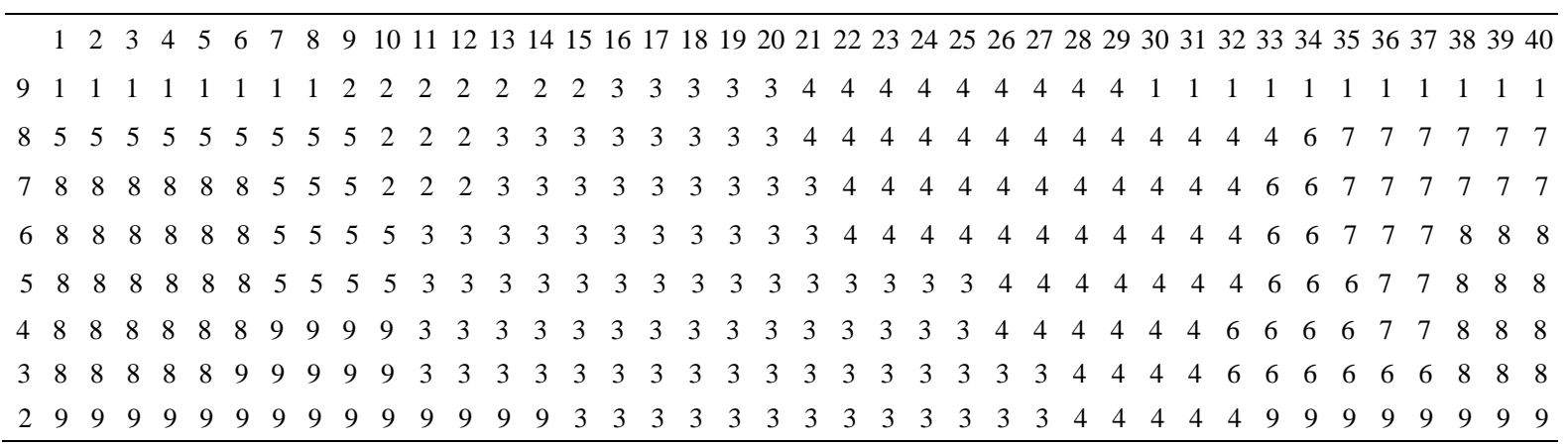

(a)

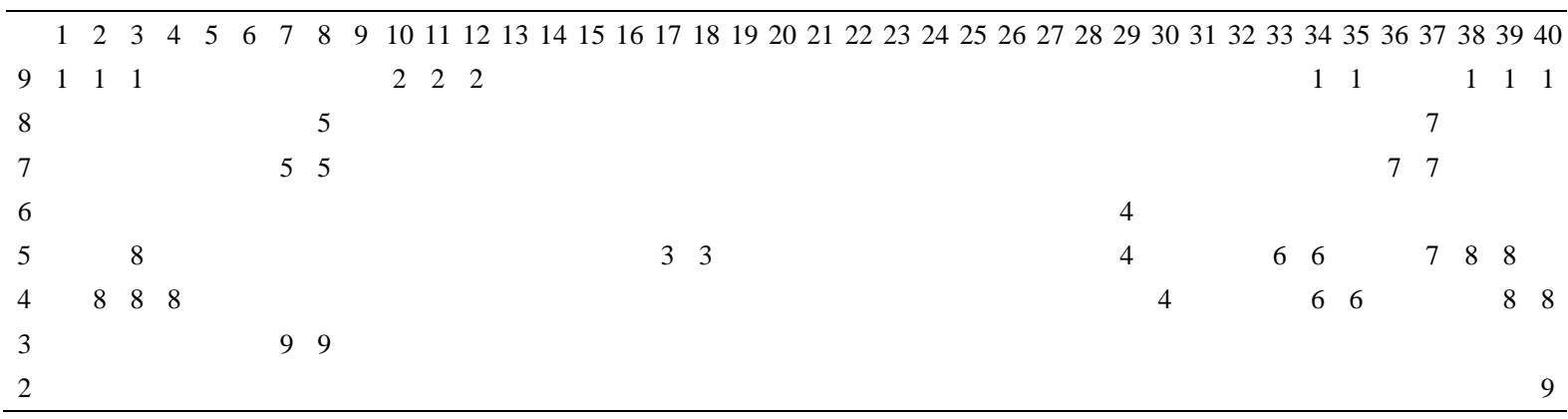

(b)

(1) abiyadh "white”; (2) asfer "yellow"; (3) akhdar "green”; (4) azrock "blue”; (5) boartoogaalee "orange”; (6) banafsagee "purple”; (7) wardee "pink"; (8) ahmar "red"; (9) bonee "brown".

Figure 1. (a) The distribution of colour categories for Arabic speakers for the 320 coloured array; (b) The numbers represent the focal points for each colour category offered by $10 \%$ of the sample and above.

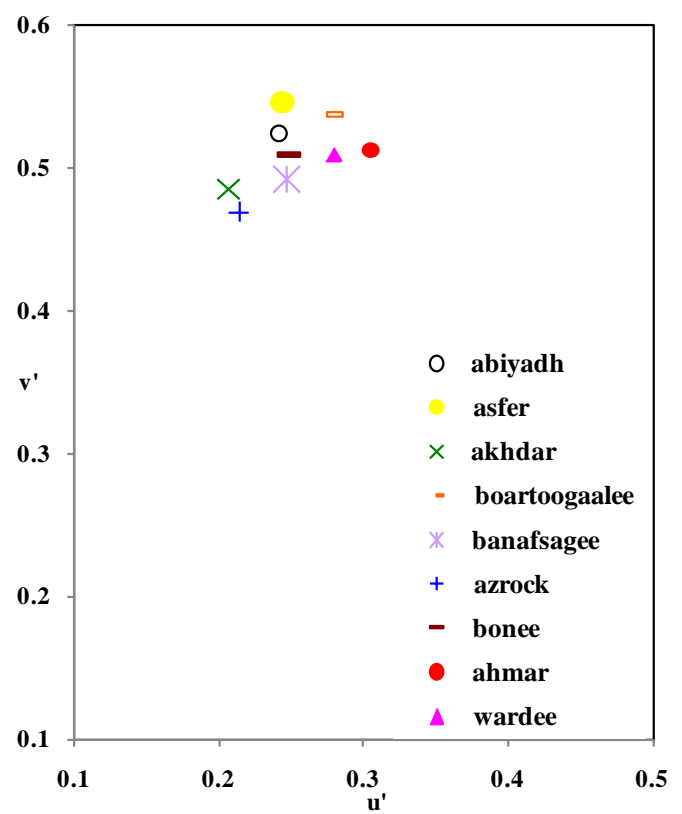

Abiyadh "white" ahmar "red", akhdar "green", asfer "yellow", azrock "blue", bonee "brown”, banafsagee "purple", wardee "pink" and boartoogaalee "orange".

Figure 2. Location of Arabic chromatic highest percentage of best example of the colour mapping in the CIE (1976) chromaticity diagram (u'v'). 
Table 1. Arabic mapping summary ( $\mathrm{N}=57$ ), term used more than once in each chip in the WCS, English glosses, the percentage of total usage (over 0.10 ), the number of chips for which a term was the most frequent, and the dominance and specificity indices.

\begin{tabular}{|c|c|c|c|c|c|c|c|}
\hline Term & Gloss & $\%$ & $\begin{array}{l}\text { No. of } \\
\text { Tile Most } \\
\text { Frequent }\end{array}$ & $\begin{array}{l}\text { No. of Chips } \\
\text { Dominant } \\
\text { D } 0.50\end{array}$ & $\begin{array}{c}\text { No. of Chips } \\
\text { Dominant } \\
\text { D } 0.75\end{array}$ & $\begin{array}{c}\text { No. of Chips } \\
\text { Dominant } \\
\text { D } 0.90\end{array}$ & $\begin{array}{l}\text { Specificity } \\
\text { Index S }\end{array}$ \\
\hline Akhdar & Green & 22.9 & 91 & 12 & 10 & 49 & 0.87 \\
\hline Azrock & Blue & 16.7 & 68 & 09 & 21 & 23 & 0.85 \\
\hline Ahmar & Red & 12.9 & 41 & 12 & 11 & 16 & 0.79 \\
\hline Banafsagee & Purple & 5.80 & 20 & 05 & 10 & 02 & 0.72 \\
\hline Wardee & Pink & 5.56 & 18 & 11 & 06 & 00 & 0.67 \\
\hline Bonee & Brown & 5.00 & 31 & 11 & 00 & 00 & 0.29 \\
\hline Abiyadh & White & 4.76 & 19 & 18 & 00 & 00 & 0.74 \\
\hline Boartoogaalee & Orange & 4.58 & 19 & 08 & 06 & 00 & 0.69 \\
\hline Asfer & Yellow & 3.91 & 13 & 04 & 03 & 04 & 0.65 \\
\hline Asswed & Black & 1.98 & 01 & 00 & 00 & 00 & 0.00 \\
\hline Samawee & Light blue & 1.44 & 00 & 00 & 00 & 00 & 0.00 \\
\hline Zeatee & Oil-green & 1.40 & 00 & 00 & 00 & 00 & 0.00 \\
\hline Rassasee & Grey & 1.04 & 00 & 00 & 00 & 00 & 0.00 \\
\hline Khuhlie & Dark blue & 0.45 & 00 & 00 & 00 & 00 & 0.00 \\
\hline Ashbee & Light green & 0.33 & 00 & 00 & 00 & 00 & 0.00 \\
\hline Beige & Beige & 0.26 & 00 & 00 & 00 & 00 & 0.00 \\
\hline Sukaree & Sugar & 0.14 & 00 & 00 & 00 & 00 & 0.00 \\
\hline \multirow[t]{2}{*}{ Fosforee } & Phosphoric & 0.12 & 00 & 00 & 00 & 00 & 0.00 \\
\hline & Fosia & 0.12 & 00 & 00 & 00 & 00 & 0.00 \\
\hline
\end{tabular}

starting with the most frequent term. For example, akhdar "green" was the most frequent term 91. As can be seen the eight chromatic Arabic colour terms: ahmar "red”, akhdar "green”, asfer "yellow”, azrock "blue”, bonee "brown”, banafsagee "purple”, wardee "pink”, boartoogaalee “orange” as well as, abiyadh "white” were only had a high frequent scores (over 3\%) in the frequency column for the sample. The second summary measure is the number of tiles for which a given term was the most frequent term across the sample (nmf). For instance, akhdar "green" was the most frequent term for 91 out of the 320 chips for the participants. It can be seen that there are 10 terms that have nmf scores of one or greater; these are the Arabic chromatic versions of the Berlin and Kay universals plus the achromatic colours abiyadh "white" and asswed "black". The nmf is an index of consensus of use, but a relatively weak one. For example, a term can be the most frequent term even though it is not used by the majority of the respondents. Also, one chip can be represented by two terms if they have the same high frequent.

Columns 5 - 7 show more stringent indices of consensus: the "Dominance" indices. A term is dominant for a particular chip if the proportion of the sample using it exceeds the given threshold. For instance, 71 chips were name akhdar "green" by at least 50\% of the sample and the D50 score for akhdar "green" is 71 . Of these 71 tiles, 59 were named akhdar by at least 75\% of the sample, and its D75 score is 59; finally of these 59 tiles, 49 were named akhdar "green" by $90 \%$ or more of the sample, and its D90 score is thus 49. It can be seen from column 5 there were nine terms that achieved dominance in both samples at the D50 criterion: ahmar "red", akhdar “green”, asfer "yellow”, azrock "blue”, banafsagee “purple”, boartoogaalee “orange”, bonee "brown”, wardee "pink” and abiyadh "white”. All of these nine terms each had at least one chips except bonee "brown”, and abiyadh "white" that achieved the D75 threshold. Only five terms met the D90 criterion.

The final column (8) shows a further measure of agreement: the specificity index. This score reaches its maximum of 1 if the term is only used to name tiles with high consensus and reaches its minimum (0) if it is never used with high consensus. The version used here is the same as that one used in experiment 2 in Al-rasheed et al., 2013 study. It can be seen that the terms that had non-zero scores are nine terms that achieved 
the D50 score the chromatic Arabic tokens of the "universals" and abiyadh "white”.

\subsection{Discussion}

The modal grouping data for Arabic basic categories in this study supported the findings of Al-rasheed et al. (2013). For the two terms Samawee ("light blue") and khuhlie ("dark blue") there was no evidence that they have basic states.

\section{General Discussions}

The result from the current study suggested that ahmar "red", akhdar "green", asfer, "yellow", azrock "blue", asswed "black", abiyadh "white”, banafsagee "purple”, boartoogaalee "orange”, bonee "brown”, wardee "pink" and rassasee, "grey" have the strongest claim to basic status. Arabic therefore corresponds perfectly with Berlin and Kay's stage VII of colour term evolution, "colour categorisation is a perceptual phenomen". These 11 terms were the most frequently offered terms in the elicitation task with scores of almost $70 \%$ or more for both samples except for rassasee, "grey" which scored about 50\% in both samples. The terms rank orders on both main measures were very similar with just minor variations in their positions. The tokens of the Kay and McDaniel's primary categories-ahmar, akhdar, asfer, azrock, asswed, and abiyadh were the six most frequent terms and they were offered by over $80 \%$ of the samples. Banafsagee, boartoogaalee, bonee, wardee, and rassasee were the next frequent terms and they are the Arabic derived categories.

All of the measures from the naming task also suggest that the eleven terms just given are probably BCTs in Arabic. They had high frequency of use, high dominance scores and high specificity indices. Although, zeatee "oil green", in the child results, and samawee "light blue", in the adult data were dominant at $50 \%$ for one tile, most other possible BCTs achieved higher dominance scores, the specificity scores $(\sim 0.30)$ were low. The same pattern of results was found in grouping task in this study. The basic eight chromatic Arabic terms were the same as those that claimed in this experiment. Samawee ("light blue") and khuhlie ("dark blue") may merit further investigation. For the current samples, they are probably not basic; exploring their status in older Arabic samples and in Arabic speakers from other regions could be interesting.

\section{Conclusion}

Arabic probably has eleven basic colour terms and these correspond with Berlin and Kay’s eleven universal categories. The terms are that ahmar "red", akhdar "green, asfer, "yellow", azrock "blue", asswed "black", abiyadh "white”, banafsagee "purple”, boartoogaalee "orange”, bonee "brown”, wardee "pink” and rassasee. Two probable secondary terms: samawee "light blue", zeatee "oil green" had the next highest claim to being basic and may deserve further investigating.

\section{References}

Al-rasheed, A., Al-mohimeed, N., \& Davies, I. (2013) Berlin and Kay’s Theory of Color Universals and Linguistic Relativity: The Case of Arabic. Journal of Modern Education Review, 3, 366-386 .

Androulaki, A., Gômez-Pestaña, N., Mitsakis, C., Lillo Jover, J., Coventry, K., \& Davies, I. R. L. (2006). Basic Colour Terms in Modern Greek: Twelve Terms. Journal of Greek Linguistics, 7, 3-47.

Berlin, B., \& Kay, P. (1969). Basic Color Terms: Their Universality and Evolution. Berkeley \& Los Angeles: University of California Press.

Davidoff, J., Davies, I., \& Roberson, D. (1999) Color Categories of a Stone-Age Tribe. Nature, 398, 203-204. http://dx.doi.org/10.1038/18335

Davies, I. R. L., \& Corbett, G. G. (1994). The Basic Color Terms of Russian. Linguistics, 32, 63-89. http://dx.doi.org/10.1515/ling.1994.32.1.65

Heider, E. R. (1971). “Focal” Color Areas and the Development of Color Names. Developmental Psychology, 4, 447-455. http://dx.doi.org/10.1037/h0030955

Heider, E. R. (1972). Universals in Color Naming and Memory. Journal of Experimental Psychology, 93, 10-20. http://dx.doi.org/10.1037/h0032606

Heider, E. R., \& Olivier, C. C. (1972). The Structure of the Color Space in Naming and Memory for Two Languages. Cognitive Psychology, 3, 337-354. http://dx.doi.org/10.1016/0010-0285(72)90011-4 
Ishihara, S. M. (1987). Ishihara's Tests for Colour-Blindness. Tokyo: Kanehara \& Co.

Jameson, K., \& D’Andrade, R. G. (1997). It’s Not Really Red, Green, Yellow, Blue: An Inquiry into Perceptual Color Space. In C. L. Hardin, \& L. Maffi (Eds.), Color Categories in Thought and Language (pp. 295-319). New York: Cambridge University Press.

Kay, P., \& McDaniel, C. (1978). The Linguistic Significance of the Meanings of Basic Color Terms. Language, 54, 610-646. http://dx.doi.org/10.1353/lan.1978.0035

Kay, P., \& Regier, T. (2003). Resolving the Question of Color Naming Universals. Proceedings of the National Academy of Sciences of the United States of America, 100, 9085-9089. http://dx.doi.org/10.1073/pnas.1532837100

Kay, P., Berlin, B., Maffi, L., \& Merrifield, W. (1997). Color Naming across Languages. In C. L. Hardin, \& L. Maffi (Eds.), Color Categories in Thought and Language (pp. 21-56). Cambridge: Cambridge University Press. http://dx.doi.org/10.1017/CBO9780511519819.002

Kay, P., Berlin, B., Maffi, L., \& Merrifield, W. (2005). World Color Survey. Chicago, IL: CSLI.

Özgen, E., \& Davies, I. R. (1998). Turkish Color Terms: Test of Berlin and Kay’s Theory of Color Universals and Linguistic Relativity. Linguistics, 36, 919-956. http://dx.doi.org/10.1515/ling.1998.36.5.919

Pich, J., \& Davies, I. R. L. (1999). Color Term Acquisition in Spanish-Catalan Children Speakers. Children and Learning, 85, 95-112.

Ratner, C. (1989). A Sociohistorical Critique of Naturalistic Theories of Color Perception. Journal of Mind and Behaviour, 10, 361-372.

Regier, T., Kay, P., \& Cook, R. S. (2005). Focal Colors Are Universal after All. Proceedings of the National Academy of Sciences of the United States of America, 102, 8386-8391. http://dx.doi.org/10.1073/pnas.0503281102

Regier, T., Kay, P., \& Khetarpal, N. (2007). Color Naming Reflects Optimal Partitions of Color Space. Proceedings of the National Academy of Sciences of the United States of America, 104, 1436-1441. http://dx.doi.org/10.1073/pnas.0610341104

Rosch, E. (1973). Natural Categories. Cognitive Psychology, 4, 328-350. http://dx.doi.org/10.1016/0010-0285(73)90017-0

Rosch, E. (1975). The Nature of Mental Codes for Categories. Journal of Experimental Psychology: Human Perception and Performance, 1, 303-322. http://dx.doi.org/10.1037/0096-1523.1.4.303

Uusküla, M. (2008). Basic Colour Terms in Finno-Ugric and Slavonic Languages: Myths and Facts. Dissertationes Linguisticae Universitatis Tartuensis, 9, Tartu: Tartu University Press, 206 p.

Zollinger, H. (1984). Why Just Turquoise? Remarks on the Evolution of Color Terms. Psychological Research, 46, $403-409$. http://dx.doi.org/10.1007/BF00309072 


\section{Appendix}

\section{Appendix 1. The Stimuli of the Experiment.}

\section{The World Colour Survey}

The world colour survey (WCS) is a large-scale of cross-cultural research into colour and language (Kay, Berlin, Maffi, \& Merrifield, 1997 \& 2005; Kay \& Regier, 2003; Regier, Kay, \& Cook, 2005). The WCS aimed to check and expand Berlin and Kay's original work, and in particular to address the shortcomings of their work. 2616 participants took part in this study, 24 male and female speakers from each of 110 unwritten languages in pre-industrialised societies. The materials used in the WCS consisted of 330 chromatic and achromatic chips of Munsell Colour System, as shown in Figure A1 each participants was asked to name in his or her language each of the 330 stimuli which presented in a stable order to all the participants. Each participant was also asked to select the best example(s) of each colour term his or her named. Result of this study which analysed the location of colour categories centroids by showing the centre of each colour category given by the sample revealed that most of these languages fall the centres of colour categories in approximately the same positions. These positions were the same as the industrialised languages known by the basic colour terms.

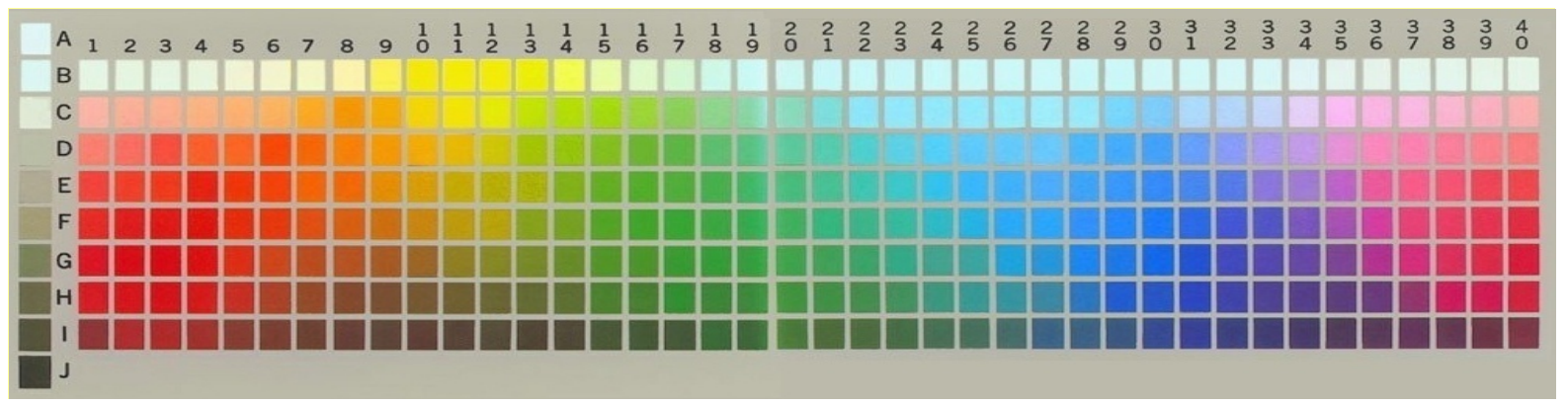

Figure A1. The (WCS) stimulus array.

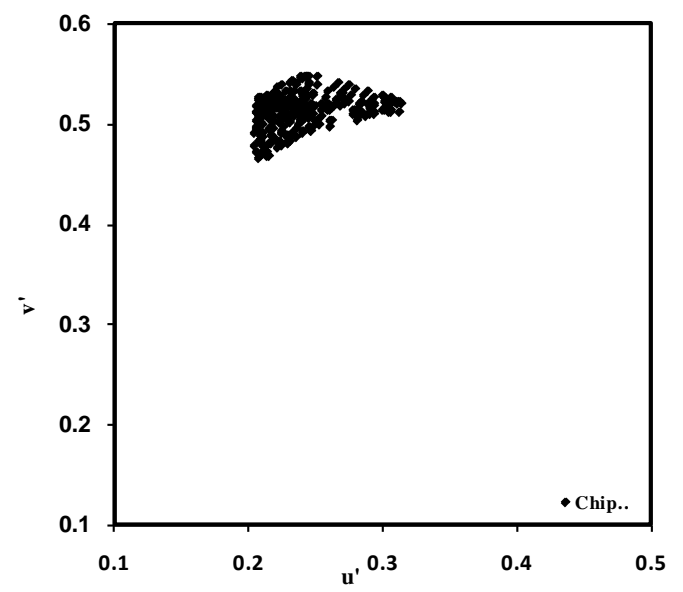

Figure A2. Location of the 230 stimuli used in the current experiment in CIE (1976) colour space (u'v'). 
Appendix 2. The CIE Yxy Chromaticity Coordinates for the Stimuli of the Experiment

Table A1. The CIE Yxy chromaticity coordinates for the 320 rectangle coloured chip in the stimulus array. Measured by MINOLTA cs-100 in the same lab that participants were tested under.

\begin{tabular}{|c|c|c|c|c|c|c|c|c|c|c|c|}
\hline \multirow{2}{*}{$\begin{array}{l}\text { Colour-Chip } \\
\text { Number }\end{array}$} & \multicolumn{5}{|c|}{ CIE Co-Ordinates } & \multirow{2}{*}{$\begin{array}{l}\text { Colour-Chip } \\
\text { Number }\end{array}$} & \multicolumn{5}{|c|}{ CIE Co-Ordinates } \\
\hline & $\mathrm{Y}$ & $\mathrm{x}$ & $\mathrm{y}$ & $\mathrm{u}^{\prime}$ & $\mathrm{v}^{\prime}$ & & $\mathrm{Y}$ & $\mathrm{x}$ & $\mathrm{y}$ & $\mathrm{u}^{\prime}$ & $\mathrm{v}^{\prime}$ \\
\hline 001 & 32.5 & 0.429 & 0.412 & 0.242 & 0.523 & 161 & 14.1 & 0.500 & 0.378 & 0.306 & 0.521 \\
\hline 002 & 30.8 & 0.430 & 0.415 & 0.242 & 0.525 & 162 & 14.2 & 0.507 & 0.374 & 0.313 & 0.520 \\
\hline 003 & 30.0 & 0.430 & 0.413 & 0.242 & 0.524 & 163 & 13.9 & 0.509 & 0.379 & 0.312 & 0.522 \\
\hline 004 & 31.5 & 0.430 & 0.415 & 0.242 & 0.525 & 164 & 13.8 & 0.507 & 0.380 & 0.310 & 0.522 \\
\hline 005 & 30.7 & 0.435 & 0.419 & 0.243 & 0.527 & 165 & 13.2 & 0.498 & 0.385 & 0.301 & 0.523 \\
\hline 006 & 34.0 & 0.437 & 0.426 & 0.242 & 0.530 & 166 & 12.0 & 0.490 & 0.392 & 0.292 & 0.525 \\
\hline 007 & 33.2 & 0.441 & 0.432 & 0.242 & 0.532 & 167 & 11.9 & 0.466 & 0.394 & 0.274 & 0.522 \\
\hline 008 & 33.8 & 0.447 & 0.436 & 0.244 & 0.535 & 168 & 11.9 & 0.463 & 0.404 & 0.268 & 0.525 \\
\hline 009 & 31.0 & 0.459 & 0.452 & 0.245 & 0.542 & 169 & 11.2 & 0.454 & 0.413 & 0.258 & 0.527 \\
\hline 010 & 32.8 & 0.467 & 0.464 & 0.245 & 0.547 & 170 & 11.6 & 0.445 & 0.420 & 0.249 & 0.529 \\
\hline 011 & 33.8 & 0.465 & 0.463 & 0.244 & 0.546 & 171 & 12.2 & 0.434 & 0.426 & 0.240 & 0.529 \\
\hline 012 & 32.6 & 0.462 & 0.464 & 0.242 & 0.546 & 172 & 11.7 & 0.427 & 0.435 & 0.232 & 0.532 \\
\hline 013 & 28.8 & 0.456 & 0.460 & 0.240 & 0.544 & 173 & 11.2 & 0.413 & 0.435 & 0.223 & 0.530 \\
\hline 014 & 23.2 & 0.443 & 0.451 & 0.235 & 0.539 & 174 & 11.5 & 0.406 & 0.435 & 0.219 & 0.529 \\
\hline 015 & 24.0 & 0.431 & 0.435 & 0.234 & 0.532 & 175 & 11.1 & 0.395 & 0.436 & 0.212 & 0.527 \\
\hline 016 & 26.3 & 0.426 & 0.430 & 0.233 & 0.530 & 176 & 10.7 & 0.387 & 0.437 & 0.207 & 0.527 \\
\hline 017 & 24.7 & 0.420 & 0.425 & 0.231 & 0.527 & 177 & 11.1 & 0.384 & 0.432 & 0.207 & 0.524 \\
\hline 018 & 22.1 & 0.414 & 0.418 & 0.230 & 0.523 & 178 & 11.2 & 0.384 & 0.416 & 0.213 & 0.518 \\
\hline 019 & 23.9 & 0.410 & 0.413 & 0.230 & 0.521 & 179 & 10.6 & 0.373 & 0.418 & 0.205 & 0.518 \\
\hline 020 & 26.0 & 0.407 & 0.409 & 0.230 & 0.519 & 180 & 10.7 & 0.369 & 0.407 & 0.207 & 0.513 \\
\hline 021 & 24.1 & 0.402 & 0.408 & 0.227 & 0.518 & 181 & 10.6 & 0.366 & 0.405 & 0.205 & 0.511 \\
\hline 022 & 25.1 & 0.402 & 0.405 & 0.228 & 0.517 & 182 & 10.2 & 0.365 & 0.398 & 0.207 & 0.508 \\
\hline 023 & 26.2 & 0.396 & 0.398 & 0.227 & 0.513 & 183 & 10.2 & 0.358 & 0.390 & 0.206 & 0.504 \\
\hline 024 & 28.9 & 0.396 & 0.396 & 0.228 & 0.512 & 184 & 10.2 & 0.349 & 0.372 & 0.206 & 0.495 \\
\hline 025 & 29.7 & 0.393 & 0.395 & 0.226 & 0.511 & 185 & 10.8 & 0.347 & 0.360 & 0.210 & 0.489 \\
\hline 026 & 28.9 & 0.388 & 0.387 & 0.226 & 0.507 & 186 & 11.2 & 0.342 & 0.351 & 0.210 & 0.484 \\
\hline 027 & 28.9 & 0.390 & 0.387 & 0.227 & 0.507 & 187 & 10.9 & 0.340 & 0.348 & 0.209 & 0.482 \\
\hline 028 & 28.5 & 0.390 & 0.386 & 0.228 & 0.507 & 188 & 10.6 & 0.332 & 0.330 & 0.211 & 0.472 \\
\hline 029 & 29.1 & 0.387 & 0.381 & 0.228 & 0.504 & 189 & 11.1 & 0.333 & 0.324 & 0.214 & 0.469 \\
\hline 030 & 32.3 & 0.395 & 0.387 & 0.231 & 0.508 & 190 & 10.0 & 0.336 & 0.328 & 0.215 & 0.471 \\
\hline 031 & 33.1 & 0.391 & 0.384 & 0.229 & 0.506 & 191 & 9.31 & 0.355 & 0.336 & 0.225 & 0.478 \\
\hline 032 & 33.6 & 0.393 & 0.385 & 0.230 & 0.507 & 192 & 9.20 & 0.367 & 0.340 & 0.231 & 0.482 \\
\hline 033 & 34.1 & 0.398 & 0.387 & 0.233 & 0.509 & 193 & 9.41 & 0.378 & 0.347 & 0.236 & 0.487 \\
\hline 034 & 36.3 & 0.405 & 0.391 & 0.235 & 0.511 & 194 & 10.5 & 0.397 & 0.352 & 0.247 & 0.493 \\
\hline 035 & 37.4 & 0.414 & 0.399 & 0.238 & 0.516 & 195 & 11.2 & 0.412 & 0.361 & 0.253 & 0.499 \\
\hline 036 & 37.0 & 0.417 & 0.403 & 0.238 & 0.518 & 196 & 11.6 & 0.449 & 0.357 & 0.281 & 0.503 \\
\hline 037 & 37.7 & 0.418 & 0.407 & 0.237 & 0.520 & 197 & 14.0 & 0.472 & 0.364 & 0.294 & 0.510 \\
\hline 038 & 38.1 & 0.418 & 0.404 & 0.238 & 0.519 & 198 & 13.9 & 0.486 & 0.364 & 0.304 & 0.512 \\
\hline 039 & 38.3 & 0.419 & 0.407 & 0.238 & 0.520 & 199 & 14.1 & 0.489 & 0.363 & 0.307 & 0.512 \\
\hline
\end{tabular}




\section{Continued}

\begin{tabular}{|c|c|c|c|c|c|c|c|c|c|c|c|}
\hline 040 & 36.4 & 0.419 & 0.405 & 0.239 & 0.519 & 200 & 14.0 & 0.489 & 0.372 & 0.302 & 0.516 \\
\hline 041 & 24.2 & 0.461 & 0.404 & 0.266 & 0.525 & 201 & 13.1 & 0.499 & 0.379 & 0.305 & 0.521 \\
\hline 042 & 23.5 & 0.466 & 0.403 & 0.270 & 0.525 & 202 & 13.5 & 0.501 & 0.378 & 0.307 & 0.521 \\
\hline 043 & 23.4 & 0.467 & 0.402 & 0.271 & 0.525 & 203 & 12.5 & 0.505 & 0.377 & 0.310 & 0.521 \\
\hline 044 & 25.2 & 0.469 & 0.407 & 0.270 & 0.527 & 204 & 12.9 & 0.507 & 0.380 & 0.310 & 0.523 \\
\hline 045 & 25.3 & 0.470 & 0.413 & 0.268 & 0.530 & 205 & 12.2 & 0.476 & 0.387 & 0.285 & 0.521 \\
\hline 046 & 25.3 & 0.474 & 0.415 & 0.270 & 0.531 & 206 & 10.9 & 0.460 & 0.392 & 0.271 & 0.520 \\
\hline 047 & 23.3 & 0.482 & 0.421 & 0.272 & 0.535 & 207 & 10.2 & 0.448 & 0.394 & 0.262 & 0.519 \\
\hline 048 & 23.4 & 0.491 & 0.428 & 0.275 & 0.538 & 208 & 9.17 & 0.446 & 0.397 & 0.260 & 0.520 \\
\hline 049 & 27.5 & 0.484 & 0.436 & 0.267 & 0.540 & 209 & 9.31 & 0.438 & 0.398 & 0.254 & 0.519 \\
\hline 050 & 32.4 & 0.474 & 0.459 & 0.251 & 0.546 & 210 & 8.58 & 0.430 & 0.401 & 0.247 & 0.519 \\
\hline 051 & 33.0 & 0.464 & 0.463 & 0.243 & 0.546 & 211 & 9.80 & 0.423 & 0.412 & 0.238 & 0.522 \\
\hline 052 & 31.1 & 0.458 & 0.466 & 0.239 & 0.546 & 212 & 9.58 & 0.420 & 0.418 & 0.234 & 0.524 \\
\hline 053 & 25.3 & 0.445 & 0.461 & 0.233 & 0.543 & 213 & 10.1 & 0.417 & 0.414 & 0.234 & 0.522 \\
\hline 054 & 23.2 & 0.440 & 0.460 & 0.230 & 0.542 & 214 & 10.2 & 0.410 & 0.421 & 0.227 & 0.524 \\
\hline 055 & 17.9 & 0.420 & 0.452 & 0.222 & 0.536 & 215 & 11.0 & 0.401 & 0.425 & 0.220 & 0.524 \\
\hline 056 & 18.0 & 0.408 & 0.432 & 0.221 & 0.528 & 216 & 11.4 & 0.399 & 0.423 & 0.219 & 0.523 \\
\hline 057 & 18.1 & 0.398 & 0.423 & 0.219 & 0.523 & 217 & 11.5 & 0.389 & 0.425 & 0.213 & 0.522 \\
\hline 058 & 18.0 & 0.392 & 0.414 & 0.218 & 0.519 & 218 & 11.1 & 0.389 & 0.424 & 0.213 & 0.522 \\
\hline 059 & 17.9 & 0.383 & 0.407 & 0.215 & 0.515 & 219 & 10.8 & 0.386 & 0.422 & 0.212 & 0.521 \\
\hline 060 & 16.4 & 0.377 & 0.403 & 0.213 & 0.512 & 220 & 11.1 & 0.387 & 0.409 & 0.217 & 0.516 \\
\hline 061 & 16.5 & 0.376 & 0.396 & 0.215 & 0.509 & 221 & 11.1 & 0.381 & 0.404 & 0.215 & 0.513 \\
\hline 062 & 19.0 & 0.378 & 0.391 & 0.218 & 0.507 & 222 & 10.4 & 0.381 & 0.400 & 0.217 & 0.512 \\
\hline 063 & 20.1 & 0.374 & 0.384 & 0.218 & 0.504 & 223 & 10.9 & 0.373 & 0.393 & 0.214 & 0.508 \\
\hline 064 & 20.7 & 0.370 & 0.378 & 0.218 & 0.501 & 224 & 10.1 & 0.380 & 0.392 & 0.219 & 0.508 \\
\hline 065 & 20.4 & 0.365 & 0.372 & 0.217 & 0.497 & 225 & 10.6 & 0.371 & 0.383 & 0.217 & 0.503 \\
\hline 066 & 20.2 & 0.361 & 0.368 & 0.216 & 0.495 & 226 & 10.6 & 0.351 & 0.362 & 0.211 & 0.491 \\
\hline 067 & 21.3 & 0.366 & 0.369 & 0.219 & 0.496 & 227 & 9.91 & 0.356 & 0.354 & 0.218 & 0.488 \\
\hline 068 & 20.2 & 0.356 & 0.356 & 0.217 & 0.488 & 228 & 10.0 & 0.346 & 0.342 & 0.216 & 0.480 \\
\hline 069 & 17.7 & 0.341 & 0.340 & 0.213 & 0.478 & 229 & 9.09 & 0.349 & 0.343 & 0.218 & 0.481 \\
\hline 070 & 18.3 & 0.345 & 0.342 & 0.215 & 0.480 & 230 & 8.58 & 0.349 & 0.334 & 0.221 & 0.476 \\
\hline 071 & 21.3 & 0.371 & 0.363 & 0.224 & 0.494 & 231 & 9.04 & 0.364 & 0.339 & 0.230 & 0.481 \\
\hline 072 & 20.6 & 0.368 & 0.358 & 0.224 & 0.491 & 232 & 8.14 & 0.372 & 0.348 & 0.231 & 0.487 \\
\hline 073 & 22.4 & 0.386 & 0.373 & 0.230 & 0.501 & 233 & 9.61 & 0.388 & 0.362 & 0.236 & 0.496 \\
\hline 074 & 25.0 & 0.406 & 0.376 & 0.242 & 0.505 & 234 & 9.64 & 0.399 & 0.360 & 0.245 & 0.497 \\
\hline 075 & 24.5 & 0.424 & 0.375 & 0.255 & 0.507 & 235 & 9.94 & 0.412 & 0.370 & 0.249 & 0.503 \\
\hline 076 & 26.1 & 0.438 & 0.383 & 0.261 & 0.513 & 236 & 10.2 & 0.426 & 0.366 & 0.261 & 0.504 \\
\hline 077 & 27.8 & 0.437 & 0.386 & 0.259 & 0.514 & 237 & 10.9 & 0.457 & 0.364 & 0.283 & 0.508 \\
\hline 078 & 27.6 & 0.441 & 0.388 & 0.260 & 0.516 & 238 & 12.3 & 0.472 & 0.369 & 0.291 & 0.512 \\
\hline 079 & 28.4 & 0.443 & 0.389 & 0.261 & 0.516 & 239 & 12.6 & 0.490 & 0.365 & 0.306 & 0.513 \\
\hline 080 & 25.2 & 0.448 & 0.392 & 0.263 & 0.518 & 240 & 12.6 & 0.484 & 0.369 & 0.300 & 0.514 \\
\hline 081 & 19.1 & 0.478 & 0.389 & 0.285 & 0.522 & 241 & 10.9 & 0.485 & 0.384 & 0.292 & 0.521 \\
\hline 082 & 16.4 & 0.486 & 0.384 & 0.293 & 0.521 & 242 & 11.4 & 0.481 & 0.384 & 0.290 & 0.520 \\
\hline
\end{tabular}




\section{Continued}

\begin{tabular}{|c|c|c|c|c|c|c|c|c|c|c|c|}
\hline 083 & 15.3 & 0.497 & 0.380 & 0.303 & 0.521 & 243 & 10.7 & 0.484 & 0.380 & 0.294 & 0.519 \\
\hline 084 & 17.1 & 0.494 & 0.393 & 0.294 & 0.526 & 244 & 10.7 & 0.473 & 0.386 & 0.283 & 0.520 \\
\hline 085 & 18.0 & 0.494 & 0.359 & 0.313 & 0.511 & 245 & 10.7 & 0.454 & 0.389 & 0.269 & 0.518 \\
\hline 086 & 16.5 & 0.505 & 0.394 & 0.301 & 0.528 & 246 & 9.16 & 0.439 & 0.392 & 0.257 & 0.517 \\
\hline 087 & 18.7 & 0.498 & 0.407 & 0.289 & 0.532 & 247 & 8.64 & 0.432 & 0.397 & 0.250 & 0.518 \\
\hline 088 & 21.0 & 0.491 & 0.417 & 0.280 & 0.534 & 248 & 8.61 & 0.425 & 0.401 & 0.244 & 0.518 \\
\hline 089 & 22.4 & 0.474 & 0.428 & 0.264 & 0.536 & 249 & 8.49 & 0.423 & 0.398 & 0.244 & 0.517 \\
\hline 090 & 22.2 & 0.462 & 0.439 & 0.252 & 0.538 & 250 & 7.97 & 0.422 & 0.401 & 0.242 & 0.518 \\
\hline 091 & 21.8 & 0.454 & 0.445 & 0.244 & 0.539 & 251 & 8.16 & 0.419 & 0.402 & 0.240 & 0.518 \\
\hline 092 & 20.1 & 0.445 & 0.453 & 0.236 & 0.540 & 252 & 8.51 & 0.415 & 0.404 & 0.237 & 0.518 \\
\hline 093 & 19.6 & 0.427 & 0.454 & 0.225 & 0.538 & 253 & 9.50 & 0.413 & 0.403 & 0.236 & 0.517 \\
\hline 094 & 17.1 & 0.413 & 0.446 & 0.220 & 0.533 & 254 & 8.94 & 0.414 & 0.404 & 0.236 & 0.518 \\
\hline 095 & 15.6 & 0.405 & 0.437 & 0.218 & 0.529 & 255 & 10.4 & 0.407 & 0.411 & 0.229 & 0.520 \\
\hline 096 & 14.4 & 0.396 & 0.434 & 0.214 & 0.527 & 256 & 10.7 & 0.404 & 0.414 & 0.226 & 0.520 \\
\hline 097 & 14.0 & 0.380 & 0.421 & 0.208 & 0.520 & 257 & 10.5 & 0.394 & 0.421 & 0.217 & 0.522 \\
\hline 098 & 15.0 & 0.378 & 0.409 & 0.211 & 0.515 & 258 & 11.0 & 0.399 & 0.413 & 0.223 & 0.519 \\
\hline 099 & 14.3 & 0.377 & 0.402 & 0.213 & 0.512 & 259 & 9.99 & 0.401 & 0.410 & 0.225 & 0.518 \\
\hline 100 & 14.0 & 0.368 & 0.394 & 0.211 & 0.507 & 260 & 10.8 & 0.396 & 0.408 & 0.223 & 0.517 \\
\hline 101 & 14.2 & 0.366 & 0.393 & 0.210 & 0.506 & 261 & 10.1 & 0.393 & 0.406 & 0.222 & 0.516 \\
\hline 102 & 13.8 & 0.361 & 0.384 & 0.210 & 0.502 & 262 & 9.80 & 0.395 & 0.397 & 0.227 & 0.512 \\
\hline 103 & 15.3 & 0.360 & 0.379 & 0.211 & 0.500 & 263 & 10.0 & 0.392 & 0.392 & 0.227 & 0.510 \\
\hline 104 & 15.0 & 0.348 & 0.364 & 0.209 & 0.491 & 264 & 9.19 & 0.384 & 0.387 & 0.223 & 0.507 \\
\hline 105 & 15.1 & 0.347 & 0.360 & 0.210 & 0.489 & 265 & 9.93 & 0.385 & 0.382 & 0.226 & 0.505 \\
\hline 106 & 15.5 & 0.345 & 0.354 & 0.210 & 0.486 & 266 & 9.69 & 0.378 & 0.376 & 0.224 & 0.501 \\
\hline 107 & 15.6 & 0.341 & 0.351 & 0.209 & 0.484 & 267 & 8.82 & 0.377 & 0.370 & 0.226 & 0.498 \\
\hline 108 & 13.9 & 0.326 & 0.331 & 0.206 & 0.471 & 268 & 9.11 & 0.368 & 0.359 & 0.224 & 0.492 \\
\hline 109 & 14.1 & 0.331 & 0.329 & 0.211 & 0.471 & 269 & 9.72 & 0.372 & 0.352 & 0.230 & 0.489 \\
\hline 110 & 13.5 & 0.333 & 0.326 & 0.213 & 0.470 & 270 & 9.02 & 0.371 & 0.353 & 0.229 & 0.489 \\
\hline 111 & 13.4 & 0.356 & 0.345 & 0.222 & 0.483 & 271 & 9.39 & 0.378 & 0.356 & 0.232 & 0.492 \\
\hline 112 & 14.2 & 0.369 & 0.347 & 0.230 & 0.486 & 272 & 9.45 & 0.387 & 0.362 & 0.236 & 0.496 \\
\hline 113 & 15.7 & 0.389 & 0.354 & 0.241 & 0.492 & 273 & 8.72 & 0.394 & 0.368 & 0.238 & 0.500 \\
\hline 114 & 16.4 & 0.403 & 0.359 & 0.248 & 0.497 & 274 & 9.33 & 0.400 & 0.372 & 0.240 & 0.502 \\
\hline 115 & 18.7 & 0.429 & 0.365 & 0.263 & 0.504 & 275 & 9.41 & 0.405 & 0.377 & 0.241 & 0.505 \\
\hline 116 & 19.7 & 0.454 & 0.369 & 0.279 & 0.509 & 276 & 9.26 & 0.410 & 0.377 & 0.245 & 0.506 \\
\hline 117 & 19.6 & 0.456 & 0.369 & 0.280 & 0.510 & 277 & 9.18 & 0.421 & 0.374 & 0.253 & 0.506 \\
\hline 118 & 18.7 & 0.460 & 0.372 & 0.281 & 0.512 & 278 & 10.8 & 0.459 & 0.369 & 0.282 & 0.510 \\
\hline 119 & 19.8 & 0.463 & 0.375 & 0.282 & 0.513 & 279 & 11.0 & 0.462 & 0.370 & 0.284 & 0.511 \\
\hline 120 & 20.2 & 0.462 & 0.377 & 0.280 & 0.514 & 280 & 11.7 & 0.458 & 0.377 & 0.277 & 0.513 \\
\hline 121 & 14.1 & 0.497 & 0.380 & 0.303 & 0.521 & 281 & 9.37 & 0.432 & 0.389 & 0.254 & 0.515 \\
\hline
\end{tabular}




\section{Continued}

\begin{tabular}{|c|c|c|c|c|c|c|c|c|c|c|c|}
\hline 122 & 13.7 & 0.503 & 0.380 & 0.307 & 0.522 & 282 & 9.72 & 0.443 & 0.388 & 0.262 & 0.516 \\
\hline 123 & 14.8 & 0.505 & 0.381 & 0.308 & 0.523 & 283 & 9.12 & 0.442 & 0.390 & 0.260 & 0.517 \\
\hline 124 & 14.3 & 0.507 & 0.379 & 0.310 & 0.522 & 284 & 9.70 & 0.435 & 0.390 & 0.256 & 0.515 \\
\hline 125 & 15.5 & 0.507 & 0.387 & 0.306 & 0.525 & 285 & 9.37 & 0.425 & 0.393 & 0.248 & 0.515 \\
\hline 126 & 15.7 & 0.505 & 0.392 & 0.302 & 0.527 & 286 & 7.91 & 0.427 & 0.393 & 0.249 & 0.515 \\
\hline 127 & 15.5 & 0.490 & 0.403 & 0.286 & 0.529 & 287 & 9.21 & 0.422 & 0.396 & 0.244 & 0.516 \\
\hline 128 & 14.7 & 0.478 & 0.407 & 0.276 & 0.529 & 288 & 8.83 & 0.419 & 0.399 & 0.241 & 0.517 \\
\hline 129 & 16.0 & 0.463 & 0.421 & 0.260 & 0.532 & 289 & 8.19 & 0.417 & 0.401 & 0.239 & 0.517 \\
\hline 130 & 16.5 & 0.448 & 0.425 & 0.249 & 0.531 & 290 & 8.79 & 0.417 & 0.400 & 0.239 & 0.517 \\
\hline 131 & 16.9 & 0.438 & 0.435 & 0.239 & 0.533 & 291 & 8.69 & 0.415 & 0.403 & 0.237 & 0.518 \\
\hline 132 & 16.2 & 0.429 & 0.440 & 0.231 & 0.534 & 292 & 8.67 & 0.416 & 0.402 & 0.238 & 0.517 \\
\hline 133 & 14.5 & 0.423 & 0.440 & 0.228 & 0.533 & 293 & 8.81 & 0.417 & 0.400 & 0.239 & 0.517 \\
\hline 134 & 13.0 & 0.404 & 0.437 & 0.217 & 0.529 & 294 & 9.84 & 0.414 & 0.401 & 0.237 & 0.517 \\
\hline 135 & 12.1 & 0.398 & 0.436 & 0.214 & 0.528 & 295 & 9.63 & 0.414 & 0.396 & 0.239 & 0.515 \\
\hline 136 & 11.6 & 0.389 & 0.434 & 0.209 & 0.526 & 296 & 8.98 & 0.415 & 0.395 & 0.240 & 0.515 \\
\hline 137 & 11.9 & 0.384 & 0.426 & 0.209 & 0.522 & 297 & 8.79 & 0.412 & 0.397 & 0.238 & 0.515 \\
\hline 138 & 11.6 & 0.376 & 0.414 & 0.208 & 0.516 & 298 & 9.34 & 0.407 & 0.403 & 0.232 & 0.517 \\
\hline 139 & 12.2 & 0.368 & 0.402 & 0.208 & 0.510 & 299 & 9.83 & 0.409 & 0.399 & 0.235 & 0.515 \\
\hline 140 & 11.8 & 0.369 & 0.401 & 0.209 & 0.510 & 300 & 9.62 & 0.412 & 0.397 & 0.238 & 0.515 \\
\hline 141 & 12.1 & 0.365 & 0.392 & 0.209 & 0.506 & 301 & 8.97 & 0.414 & 0.399 & 0.238 & 0.516 \\
\hline 142 & 11.5 & 0.357 & 0.383 & 0.208 & 0.501 & 302 & 8.67 & 0.413 & 0.398 & 0.238 & 0.515 \\
\hline 143 & 11.4 & 0.352 & 0.377 & 0.207 & 0.498 & 303 & 8.88 & 0.407 & 0.396 & 0.235 & 0.514 \\
\hline 144 & 12.0 & 0.344 & 0.367 & 0.205 & 0.492 & 304 & 9.91 & 0.410 & 0.389 & 0.240 & 0.511 \\
\hline 145 & 11.7 & 0.338 & 0.350 & 0.207 & 0.483 & 305 & 9.34 & 0.409 & 0.390 & 0.238 & 0.512 \\
\hline 146 & 11.8 & 0.330 & 0.344 & 0.204 & 0.479 & 306 & 9.13 & 0.408 & 0.393 & 0.237 & 0.513 \\
\hline 147 & 12.3 & 0.338 & 0.340 & 0.211 & 0.478 & 307 & 9.20 & 0.399 & 0.383 & 0.235 & 0.507 \\
\hline 148 & 12.4 & 0.327 & 0.324 & 0.210 & 0.468 & 308 & 9.77 & 0.403 & 0.381 & 0.238 & 0.507 \\
\hline 149 & 11.2 & 0.324 & 0.323 & 0.208 & 0.467 & 309 & 9.81 & 0.403 & 0.379 & 0.239 & 0.506 \\
\hline 150 & 10.3 & 0.334 & 0.324 & 0.215 & 0.469 & 310 & 10.0 & 0.399 & 0.374 & 0.239 & 0.503 \\
\hline 151 & 10.0 & 0.358 & 0.344 & 0.223 & 0.483 & 311 & 9.87 & 0.397 & 0.372 & 0.238 & 0.502 \\
\hline 152 & 10.5 & 0.365 & 0.340 & 0.230 & 0.482 & 312 & 8.58 & 0.400 & 0.375 & 0.239 & 0.504 \\
\hline 153 & 12.2 & 0.386 & 0.351 & 0.240 & 0.491 & 313 & 9.91 & 0.404 & 0.380 & 0.239 & 0.507 \\
\hline 154 & 12.6 & 0.398 & 0.353 & 0.247 & 0.493 & 314 & 8.92 & 0.410 & 0.386 & 0.241 & 0.510 \\
\hline 155 & 12.1 & 0.419 & 0.355 & 0.261 & 0.498 & 315 & 8.40 & 0.414 & 0.390 & 0.242 & 0.512 \\
\hline 156 & 15.2 & 0.462 & 0.363 & 0.287 & 0.508 & 316 & 8.13 & 0.409 & 0.392 & 0.238 & 0.512 \\
\hline 157 & 16.1 & 0.469 & 0.366 & 0.291 & 0.510 & 317 & 8.36 & 0.410 & 0.389 & 0.240 & 0.511 \\
\hline 158 & 15.6 & 0.474 & 0.368 & 0.293 & 0.512 & 318 & 8.47 & 0.416 & 0.387 & 0.244 & 0.511 \\
\hline 159 & 14.8 & 0.486 & 0.367 & 0.302 & 0.514 & 319 & 8.23 & 0.418 & 0.387 & 0.246 & 0.512 \\
\hline 160 & 15.8 & 0.478 & 0.377 & 0.291 & 0.517 & 320 & 8.79 & 0.420 & 0.383 & 0.249 & 0.510 \\
\hline
\end{tabular}


Table A2. Highest percentage of tile-naming in the colour mapping: Colour-Chip number, terms used, their English glosses, the percentage of highest total usage, and the average CIE co-ordinates along with the loci of the 11 universal colour foci (Heider, 1971).

\begin{tabular}{|c|c|c|c|c|c|c|c|}
\hline \multirow{3}{*}{ Colour-Chip } & \multirow{3}{*}{ Term } & \multirow{3}{*}{ Gloss } & \multirow{3}{*}{$\%$} & \multicolumn{4}{|c|}{ Average CIE Co-Ordinates } \\
\hline & & & & \multirow{2}{*}{$\mathrm{u}^{\prime}$} & \multirow{2}{*}{$\mathrm{v}^{\prime}$} & \multicolumn{2}{|c|}{ Universals } \\
\hline & & & & & & $\mathrm{u}^{\prime}$ & $\mathrm{v}^{\prime}$ \\
\hline C 001 & Abiyadh & White & 41 & 0.24 & 0.52 & 0.20 & 0.47 \\
\hline C 011 & Asfer & Yellow & 48 & 0.24 & 0.55 & 0.24 & 0.55 \\
\hline С 048 & Boartoogaalee & Orange & 32 & 0.28 & 0.54 & 0.34 & 0.52 \\
\hline C 117 & Wardee & Pink & 22 & 0.28 & 0.51 & 0.21 & 0.47 \\
\hline C 177 & Akhdar & Green & 17 & 0.21 & 0.52 & 0.13 & 0.48 \\
\hline C 189 & Azrock & Blue & 25 & 0.21 & 0.47 & 0.16 & 0.32 \\
\hline C 194 & Banafsagee & Purple & 23 & 0.25 & 0.49 & 0.23 & 0.34 \\
\hline C 239 & Ahmar & Red & 30 & 0.31 & 0.51 & 0.40 & 0.51 \\
\hline C 320 & Bonee & Brown & 73 & 0.25 & 0.51 & 0.23 & 0.48 \\
\hline
\end{tabular}

Table A3. Detailed results of the colour mapping task $(\mathrm{N}=57)$, the most frequent responses given to each "colour chip” and the percentage (over $10 \%$ ) with which they were given (Code = WCS, \% = percentage of respondents who used a term for a given tile).

\begin{tabular}{|c|c|c|c|c|c|c|c|c|c|c|c|c|c|c|c|c|c|}
\hline Code & Terms & $\%$ & Code & Terms & $\%$ & Code & Terms & $\%$ & Code & Terms & $\%$ & Code & Terms & $\%$ & Code & Terms & $\%$ \\
\hline $\mathrm{C} 1$ & White & 50.9 & $\mathrm{C} 2$ & White & 63.2 & C3 & White & 61.4 & C4 & White & 70.2 & C5 & White & 66.7 & C6 & White & 66.7 \\
\hline \multirow[t]{2}{*}{ C7 } & White & 59.6 & C8 & White & 43.9 & C9 & Yellow & 94.7 & C10 & Yellow & 82.5 & C11 & Yellow & 59.6 & C12 & Yellow & 84.2 \\
\hline & Yellow & 14.0 & & Yellow & 28.1 & & & & & & & & & & & & \\
\hline \multirow[t]{3}{*}{ C13 } & Yellow & 98.2 & C14 & Yellow & 93.0 & C15 & Yellow & 36.8 & C16 & Green & 33.3 & C17 & Green & 36.8 & C18 & Green & 29.8 \\
\hline & & & & & & & Green & 26.3 & & White & 15.8 & & White & 17.5 & & White & 24.6 \\
\hline & & & & & & & & & & Yellow & 14.0 & & & & & & \\
\hline \multirow[t]{3}{*}{ C19 } & Green & 29.8 & C20 & Green & 26.3 & C21 & Blue & 29.8 & C22 & Blue & 31 & C23 & Blue & 31.6 & $\mathrm{C} 24$ & Blue & 29.8 \\
\hline & White & 24.6 & & White & 24.6 & & White & 24.6 & & White & 24.6 & & White & 24.6 & & White & 24.6 \\
\hline & & & & & & & L blue & 15.8 & & L blue & 17.5 & & L blue & 12.3 & & L blue & 17.5 \\
\hline \multirow[t]{3}{*}{ C25 } & Blue & 29.8 & C26 & Blue & 29.8 & C27 & Blue & 29.8 & C28 & Blue & 29.8 & C29 & Blue & 29.8 & C30 & White & 50.9 \\
\hline & White & 26.3 & & White & 28.1 & & White & 24.6 & & White & 26.3 & & White & 28.1 & & Blue & 17.5 \\
\hline & L blue & 15.8 & & L blue & 15.8 & & L blue & 17.5 & & L blue & 17.5 & & L blue & 17.5 & & & \\
\hline \multirow[t]{2}{*}{ C31 } & White & 52.6 & C32 & White & 57.9 & C33 & White & 66.7 & C34 & White & 57.9 & C35 & White & 68.4 & C36 & White & 73.7 \\
\hline & Blue & 17.5 & & Blue & 14.0 & & & & & & & & & & & & \\
\hline \multirow[t]{3}{*}{ C37 } & White & 71.9 & C38 & White & 68.4 & C39 & White & 63.2 & $\mathrm{C} 40$ & White & 61.4 & C41 & Orange & 40.4 & $\mathrm{C} 42$ & Orange & 40.4 \\
\hline & & & & & & & & & & & & & Red & 19.3 & & Pink & 25.0 \\
\hline & & & & & & & & & & & & & Pink & 15.8 & & Red & 19.3 \\
\hline \multirow[t]{3}{*}{ C43 } & Orange & 45.6 & C44 & Orange & 70.2 & C45 & Orange & 84.2 & $\mathrm{C} 46$ & Orange & 82.5 & C47 & Orange & 84.2 & C48 & Orange & 63.2 \\
\hline & Red & 19.3 & & & & & & & & & & & & & & & \\
\hline & Pink & 17.5 & & & & & & & & & & & & & & & \\
\hline \multirow[t]{2}{*}{ C49 } & Orange & 80.7 & C50 & Yellow & 63.2 & C51 & Yellow & 89.5 & C52 & Yellow & 94.6 & C53 & Green & 56.1 & C54 & Green & 64.9 \\
\hline & & & & Orange & 15.8 & & & & & & & & Yellow & 24.6 & & Yellow & 19.3 \\
\hline C55 & Green & 91.2 & C56 & Green & 93.0 & C57 & Green & 94.7 & C58 & Green & 93.0 & C59 & Green & 91.2 & C60 & Green & 86.0 \\
\hline \multirow[t]{2}{*}{ C61 } & Blue & 73.7 & C62 & Blue & 80.7 & C63 & Blue & 80.7 & C64 & Blue & 78.9 & C65 & Blue & 78.9 & C66 & Blue & 78.9 \\
\hline & & & & L blue & 14.0 & & L blue & 12.3 & & L blue & 11.0 & & L blue & 14.0 & & L blue & 15.8 \\
\hline
\end{tabular}




\section{Continued}

\begin{tabular}{|c|c|c|c|c|c|c|c|c|c|c|c|c|c|c|c|c|c|}
\hline \multirow[t]{2}{*}{ C67 } & Blue & 78.9 & C68 & Blue & 77.2 & C69 & Blue & 89.5 & C70 & Blue & 89.5 & C71 & Blue & 80.7 & C72 & Blue & 80.7 \\
\hline & L blue & 15.8 & & L blue & 15.8 & & & & & & & & L blue & 14.0 & & L blue & 14.0 \\
\hline \multirow[t]{2}{*}{ C73 } & Blue & 71.9 & C74 & Purple & 47.4 & C75 & Pink & 80.7 & C76 & $\mathrm{nk}$ & 86.0 & C77 & $\mathrm{nk}$ & 80.7 & C78 & $\mathrm{nk}$ & 84.2 \\
\hline & & & & Pink & 36.8 & & & & & & & & & & & & \\
\hline \multirow[t]{2}{*}{ C79 } & Pink & 82.5 & C80 & Pink & 78.9 & C81 & Red & 77.2 & C82 & d & 77.2 & C83 & Red & 86.0 & C84 & Red & 75.4 \\
\hline & & & & & & & & & & & & & & & & Drange & 14.0 \\
\hline \multirow[t]{2}{*}{ C85 } & ed & 73.7 & C86 & ed & 84.2 & C87 & Orange & 59.6 & C88 & Orange & 70.2 & C89 & Orange & 77.2 & C90 & Yellow & 36.8 \\
\hline & Orange & 15.8 & & Orange & 12.3 & & Red & 26.3 & & Red & 14.0 & & & & & Orange & 31.6 \\
\hline \multirow[t]{2}{*}{ C91 } & Yellow & 56.1 & C92 & Yellow & 49.1 & C93 & Green & 82.5 & C94 & Green & 93.0 & C95 & Green & 93.0 & C96 & een & 96.5 \\
\hline & Green & 12.3 & & Green & 35.1 & & & & & & & & & & & & \\
\hline C97 & Green & 98.2 & C98 & Green & 98.2 & C99 & Green & 98.2 & C100 & Green & 96.5 & C101 & Green & 89.5 & C102 & Blue & 71.9 \\
\hline C103 & Blue & 80.7 & 104 & Blue & 94.7 & C105 & Blue & 94.7 & C106 & Blue & 93.0 & C107 & lue & 91.2 & C108 & lue & 96.5 \\
\hline C109 & Blue & 93.0 & C110 & Blue & 94.7 & C111 & Blue & 89.5 & C112 & Blue & 87.7 & C113 & Purple & 87.7 & C114 & Purple & 93.0 \\
\hline \multirow[t]{2}{*}{ C115 } & Pink & 64.9 & C116 & Pink & 68.4 & C117 & Pink & 59.6 & C118 & Pink & 71.9 & C119 & Pink & 66.7 & C120 & Pink & 64.9 \\
\hline & Purple & 19.3 & & & & & Red & 17.5 & & Red & 19.3 & & Red & 28.1 & & Red & 29.8 \\
\hline C121 & Red & 96.5 & C122 & Red & 98.2 & C123 & Red & 96.5 & C124 & Red & 93.0 & C125 & Red & 93.0 & C126 & Red & 89.5 \\
\hline \multirow[t]{2}{*}{ C127 } & range & 63.2 & C128 & Orange & 71.9 & C129 & range & 80.7 & C130 & Orange & 40.4 & C131 & Green & 49.1 & C132 & reen & 71.9 \\
\hline & Red & 24.6 & & Red & 14.0 & & & & & Yellow & 28.1 & & Yellow & 29.8 & & Yellow & 12.3 \\
\hline C133 & Green & 86.0 & C134 & Green & 96.5 & C135 & Green & 96.5 & C136 & Green & 96.5 & C137 & Green & 94.7 & C138 & Green & 94.7 \\
\hline \multirow[t]{2}{*}{ C139 } & Green & 98.2 & C140 & Green & 98.2 & C141 & Green & 96.5 & C142 & te & 54.4 & C143 & lue & 70.2 & C144 & lue & 93.0 \\
\hline & & & & & & & & & & Green & 35.1 & & Green & 19.3 & & & \\
\hline C145 & Blue & 94.7 & C146 & Blue & 94.7 & C147 & ue & 89.5 & C148 & ue & 94.7 & C149 & lue & 80.7 & C150 & Blue & 93.0 \\
\hline \multirow[t]{2}{*}{ C151 } & Blue & 96.5 & C152 & Blue & 82.5 & C153 & Purple & 91.2 & C154 & Purple & 89.5 & C155 & Purple & 80.7 & C156 & Pink & 71.9 \\
\hline & & & & & & & & & & & & & & & & Red & 19.3 \\
\hline \multirow[t]{2}{*}{ C157 } & Pink & 68.4 & C158 & Pink & 43.9 & C159 & Red & 64.9 & C160 & & 63.2 & C161 & Red & 96.5 & C162 & Red & 96.5 \\
\hline & Red & 24.6 & & Red & 42.1 & & & & & Pink & 33.3 & & & & & & \\
\hline \multirow[t]{2}{*}{ C163 } & Red & 86.0 & C164 & Red & 93.0 & C165 & Red & 96.5 & C166 & Red & 91.2 & C167 & Red & 54.4 & C168 & Orange & 66.7 \\
\hline & & & & & & & & & & & & & & 33.3 & & & 17.5 \\
\hline \multirow[t]{2}{*}{ C169 } & Orange & 56.1 & C170 & Orange & 40.4 & C171 & Green & 70.2 & C172 & en & 70.2 & C173 & Green & 93.0 & C174 & Green & 94.7 \\
\hline & Brown & 17.5 & & Yellow & 14.0 & & & & & & & & & & & & \\
\hline C175 & Green & 100.00 & C & Green & 100.0 & C & C & 84.2 & C & G & 89.5 & 79 & en & 93.0 & 80 & en & 91.2 \\
\hline C181 & Green & 94.7 & C182 & Green & 96.5 & C183 & Green & 89.5 & C184 & ue & 82.5 & C185 & Blue & 91.2 & C186 & Blue & 91.2 \\
\hline \multirow[t]{2}{*}{ C187 } & Blue & 94.7 & C188 & Blue & 96.5 & C189 & Blue & 78.9 & C190 & Blue & 100.0 & C191 & Blue & 91.2 & C192 & Blue & 47.4 \\
\hline & & & & & & & & & & & & & & & & ple & 38.6 \\
\hline \multirow[t]{2}{*}{ C193 } & Purple & 54.4 & C194 & irple & 77.2 & C195 & $\mathrm{P}$ & 89.5 & C196 & $\mathrm{k}$ & 59.6 & C197 & Pink & 52.6 & C198 & Red & 54.4 \\
\hline & Blue & 29.8 & & & & & & & & Red & 24.6 & & Red & 33.3 & & Pink & 35.1 \\
\hline \multirow[t]{2}{*}{ C199 } & Red & 59.6 & C200 & Red & 68.4 & C201 & Red & 96.5 & C202 & Red & 89.5 & C203 & Red & 86.0 & C204 & Red & 84.2 \\
\hline & Pink & 28.1 & & Pink & 29.8 & & & & & & & & & & & & \\
\hline \multirow[t]{2}{*}{ C205 } & Red & 96.5 & C206 & Red & 49.1 & C207 & $\mathrm{Brc}$ & 56.1 & C208 & Brown & 59.6 & C209 & Brown & 56.1 & C210 & Brown & 49.1 \\
\hline & & & & Brown & 38.6 & & кен & 22.8 & & кеш & 15.8 & & & & & & \\
\hline C211 & Green & 08.4 & C212 & Green & 68.4 & C213 & Green & 77.2 & C214 & Green & 86.0 & C215 & Green & 100 & C216 & Green & 100 \\
\hline C217 & Green & 98.2 & C218 & Green & 6.5 & C219 & en & 94.7 & C220 & Green & 96.5 & C221 & Green & 100 & C222 & Green & 30.2 \\
\hline C223 & reen & 100 & C224 & Green & 94.7 & C225 & Green & 89.5 & C226 & 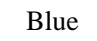 & 93.0 & C227 & Blue & 94.7 & C228 & Blue & 98. \\
\hline
\end{tabular}




\section{Continued}

\begin{tabular}{|c|c|c|c|c|c|c|c|c|c|c|c|c|c|c|c|c|c|}
\hline \multirow[t]{2}{*}{ C229 } & Blue & 98.2 & $\mathrm{C} 230$ & Blue & 78.9 & $\mathrm{C} 231$ & Blue & 71.9 & C232 & Purple & 47.4 & C233 & Purple & 64.9 & C234 & Purple & 86.0 \\
\hline & & & & & & & & & & Blue & 45.6 & & Blue & 24.6 & & & \\
\hline \multirow[t]{2}{*}{ C235 } & Purple & 86.0 & C236 & Purple & 59.6 & C237 & Pink & 54.4 & C238 & Red & 66.7 & C239 & Red & 56.1 & C240 & Red & 66.7 \\
\hline & & & & Pink & 21.1 & & Red & 38.6 & & Pink & 33.3 & & Pink & 33.3 & & Pink & 33.3 \\
\hline \multirow[t]{2}{*}{ C241 } & Red & 94.7 & C242 & Red & 98.2 & C243 & Red & 98.2 & C244 & Red & 96.5 & C245 & Red & 84.2 & C246 & Brown & 49.1 \\
\hline & & & & & & & & & & & & & & & & Red & 33.3 \\
\hline \multirow[t]{2}{*}{ C247 } & Brown & 59.6 & C248 & Brown & 49.1 & C249 & Brown & 64.9 & C250 & Brown & 50.9 & C251 & Green & 28.1 & C252 & Green & 33.3 \\
\hline & & & & & & & & & & & & & Brown & 24.6 & & Brown & 15.8 \\
\hline \multirow[t]{2}{*}{ C253 } & Green & 35.1 & C254 & Green & 38.6 & C255 & Green & 98.2 & C256 & Green & 100 & C257 & Green & 93.0 & C258 & Green & 100 \\
\hline & Brown & 15.8 & & Brown & 12.3 & & & & & & & & & & & & \\
\hline C259 & Green & 100 & C260 & Green & 100. & C261 & Green & 100 & C262 & Green & 100 & C263 & Green & 100 & C264 & Green & 96.5 \\
\hline \multirow[t]{2}{*}{ C265 } & Green & 91.2 & C266 & Green & 70.2 & C267 & Green & 64.9 & C268 & Blue & 89.5 & C269 & Blue & 73.7 & C270 & Blue & 70.2 \\
\hline & & & & Blue & 19.3 & & Blue & 28.1 & & & & & Purple & 17.5 & & Purple & 21.1 \\
\hline \multirow[t]{2}{*}{ C271 } & Blue & 64.9 & C272 & Purple & 43.9 & C273 & Purple & 70.2 & C274 & Purple & 86.0 & C275 & Purple & 84.2 & C276 & Purple & 75.4 \\
\hline & Purple & 24.6 & & Blue & 42.1 & & Blue & 19.3 & & & & & & & & & \\
\hline \multirow[t]{2}{*}{ C277 } & Purple & 66.7 & C278 & Red & 70.2 & C279 & Red & 66.7 & C280 & Red & 66.7 & C281 & Brown & 47.8 & C282 & Brown & 47.4 \\
\hline & & & & Pink & 29.8 & & Pink & 29.8 & & Pink & 29.8 & & Red & 22.8 & & Red & 28.1 \\
\hline \multirow[t]{2}{*}{ C283 } & Brown & 45.6 & C284 & Brown & 42.1 & C285 & brown & 56.1 & C286 & brown & 54.4 & C287 & brown & 47.8 & C288 & brown & 40.4 \\
\hline & Red & 28.1 & & Red & 28.1 & & black & 12.3 & & black & 12.3 & & black & 22.8 & & black & 28.1 \\
\hline \multirow[t]{2}{*}{ C289 } & brown & 35.1 & C290 & brown & 35.1 & C291 & Brown & 29.8 & C292 & brown & 28.9 & C293 & brown & 28.9 & C294 & brown & 28.9 \\
\hline & black & 29.8 & & black & 31.6 & & Black & 26.3 & & black & 22.8 & & black & 24.6 & & black & 24.6 \\
\hline \multirow[t]{2}{*}{ C295 } & Green & 29.8 & C296 & Green & 31.6 & C297 & Green & 36.8 & C298 & Green & 64.9 & C299 & Green & 64.9 & C300 & Green & 64.9 \\
\hline & Black & 15.8 & & Black & 15.8 & & Black & 12.3 & & & & & & & & & \\
\hline \multirow[t]{2}{*}{ С301 } & Green & 36.8 & C302 & Green & 45.7 & С303 & Green & 36.8 & C304 & Green & 35.1 & C205 & Green & 35.1 & C306 & Green & 26.3 \\
\hline & & & & & & & Black & 12.3 & & Black & 12.3 & & Black & 12.3 & & & \\
\hline \multirow[t]{4}{*}{ С307 } & Green & 17.5 & С308 & Blue & 19.3 & С309 & Blue & 22.8 & C310 & Blue & 35.1 & C311 & Blue & 35.1 & C312 & Blue & 17.5 \\
\hline & Blue & 14.0 & & Green & 14.0 & & & & & Purple & 17.5 & & Purple & 19.3 & & Brown & 15.8 \\
\hline & & & & & & & & & & & & & & & & Black & 15.8 \\
\hline & & & & & & & & & & & & & & & & urple & 12.3 \\
\hline \multirow[t]{4}{*}{ C313 } & Brown & 19.3 & C314 & Brown & 22.8 & C315 & Brown & 24.6 & C316 & Brown & 24.6 & C317 & Brown & 24.6 & C318 & Brown & 28.1 \\
\hline & Black & 19.3 & & Purple & 17.5 & & Black & 19.3 & & Black & 17.5 & & Black & 17.5 & & Black & 15.8 \\
\hline & purple & 14.0 & & Black & 15.8 & & purple & 17.5 & & purple & 15.8 & & purple & 15.8 & & purple & 15.8 \\
\hline & & & & grey & 12.3 & & & & & grey & 12.3 & & grey & 12.3 & & & \\
\hline \multirow[t]{3}{*}{ C319 } & Brown & 29.8 & C320 & Brown & 15.8 & & & & & & & & & & & & \\
\hline & purple & 15.8 & & purple & 15.8 & & & & & & & & & & & & \\
\hline & Black & 14.0 & & Black & 14.0 & & & & & & & & & & & & \\
\hline
\end{tabular}


Scientific Research Publishing (SCIRP) is one of the largest Open Access journal publishers. It is currently publishing more than 200 open access, online, peer-reviewed journals covering a wide range of academic disciplines. SCIRP serves the worldwide academic communities and contributes to the progress and application of science with its publication.

Other selected journals from SCIRP are listed as below. Submit your manuscript to us via either submit@scirp.org or Online Submission Portal.
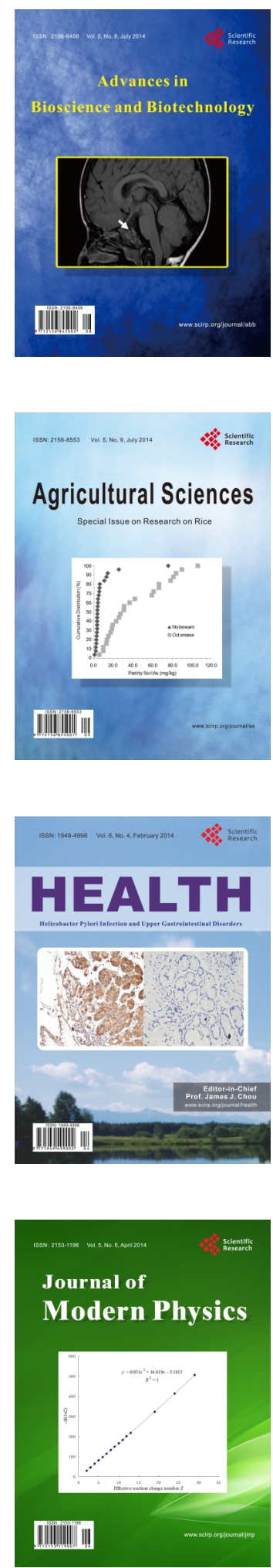
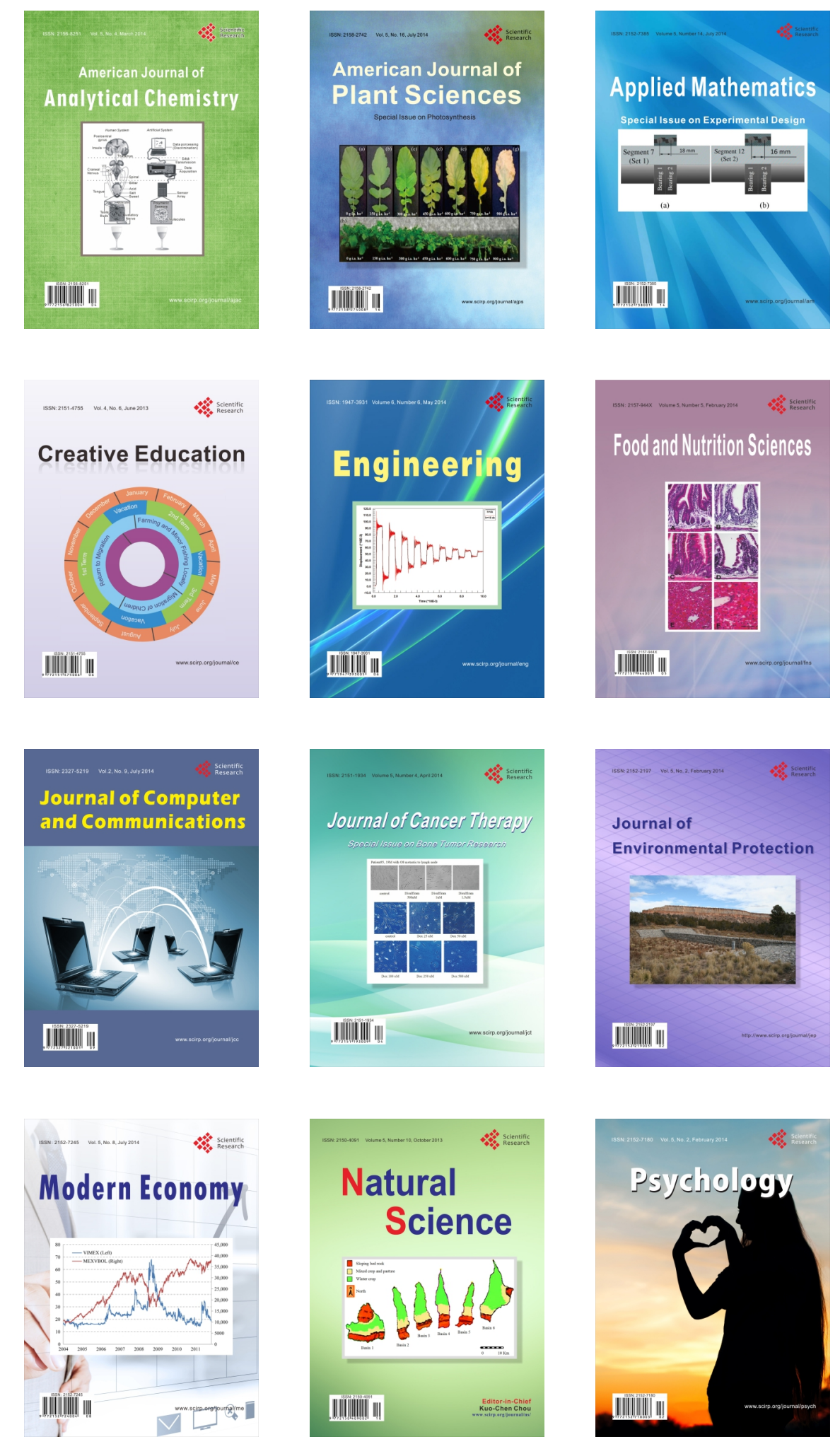